\title{
Selective Estrogen Receptor Modulator TAS-108
}

National Cancer Institute

\section{Source}

National Cancer Institute. Selective Estrogen Receptor Modulator TAS-108. NCI

Thesaurus. Code C61494.

A synthetic, antiestrogenic steroidal compound with potential antitumor activity. TAS-108 binds to and inhibits estrogenic receptor alpha (ERa), mainly expressed in the mammary gland and uterus and upregulated in estrogen-dependent tumors. Blockage of ERa by TAS-108 prevents the binding and effects of estrogen and may lead to an inhibition of estrogen-dependent cancer cell proliferation. TAS-108 also is a partial agonist of the estrogenic receptor beta (ERb), expressed in many tissues including the central nervous system, urogenital tract, bone and cardiovascular system, thereby exerting a positive effect on these tissues. In addition, TAS-108 activates the co-repressor Silencing Mediator for Retinoid and Thyroid hormone receptor (SMRT), a protein that inhibits the activities of the estrogen receptors, which may contribute to the antitumor activity of TAS-108. 